\title{
STRUKTUR DAN KOMPOSISI FITOPLANKTON DI BAGIAN HULU SUNGAI SALUESEM, MINAHASA, SULAWESI UTARA
}

\author{
Amanda T.C Nalang ${ }^{1)}$, Herni E.I. Simbala ${ }^{1)}$, Nio Song Ai ${ }^{1)}$, Ratna Siahaan ${ }^{1)}$ \\ ${ }^{1)}$ Jurusan Biologi FMIPA Universitas Sam Ratulangi Manado \\ e-mail: amandanalang@gmail.com; hsimbala@yahoo.co.id; nio_ai@yahoo.com \\ Ratna245_siahaan@yahoo.com
}

\begin{abstract}
ABSTRAK
Sungai Saluesem termasuk perairan terbuka yang mengalir (lotik) yang berasal dari Gunung Mahawu, Minahasa dan bermuara ke Teluk Manado yang terletak di Kota Manado, Sulawesi Utara. Hulu sungai merupakan daerah konservasi tanah dan air yang sangat penting dalam mempertahankan kualitas air Sungai Saluesem dari hulu hingga hilir. Kegiatan manusia dari permukiman, pertanian dan peternakan yang terus meningkat di hulu Sungai Saluesem dapat menyebabkan terjadinya penurunan kualitas perairan. Tujuan penelitian adalah menganalisis struktur dan komposisi fitoplankton bagian hulu Sungai Saluesem, Minahasa, Sulawesi Utara. Penelitian dilaksanakan dari Oktober 2014 sampai Desember 2014. Penelitian menggunakan metode purposive random sampling. Pengulangan dilakukan sebanyak 3 kali ulangan di tiap titik pengamatan, dengan demikian terdapat enam titik ( 2 x 3$)$ pengamatan di hulu.Fitoplankton yang didapatkan di hulu Sungai Saluesem sebanyak 1700 individu dari 32 spesies dan 3 kelas. Kelas fitoplankton yaitu Bacillariophyceae, Chlorophyceae, dan Cyanophyceae. Kepadatan tertinggi berasal dari Kelas Bacillariophyceae 2214 individu $/ \mathrm{m}^{3}$ (84\%) diikuti Kelas Chlorophyceae 349 individu $/ \mathrm{m}^{3}$ (13\%) lalu Cyanophyceae 72 individu $/ \mathrm{m}^{3}$ (3\%). Indeks keanekaragaman di Hulu Sungai Saluesem yaitu 2,92 yang termasuk keanekaragaman sedang. Distribusi Spesies fitoplankton di bagian hulu merata dengan indeks kemerataan (E) yaitu 0,64. Tidak ada spesies fitoplankton yang mendominasi di Hulu Sungai dengan indeks dominansi mendekati nol yaitu 0,18. Kualitas air Sungai Saluesem bagian hulu dikategorikan tercemar ringan dengan indeks H' yaitu 2,92. Sumber pencemaran di lokasi penelitian diduga berasal dari kegiatan rumahtangga (MCK) dan peternakan.
\end{abstract}

Kata Kunci: Sungai Saluesem, Struktur Fitoplankton, Komposisi fitoplankton, Kualitas Air, Sulawesi Utara

\section{STRUCTURE AND COMPOSITION OF PHYTOPLANKTON OF UPSTREAM SALUESEUM RIVER, MINAHASA, NORTH SULAWESI}

\begin{abstract}
Saluesem River is a lotic ecosystem that started from Mahawu Mountain, Minahasa and to Manado Bay, North Sulawesi. Upstream Salusem River is an important soil and water conservation area for to maintain quality of Salusem River from upstream to downstream. Increasing human activities from settlement, agriculture and animal husbandry can decrease quality of Salusem River. The aim of this research was to analysis phytoplankton structure and composition of upper Salusem River, Minahasa, North Sulawesi. The research was conducted from October 2014 to December 2014. The study applied purposive random sampling method with three repetitions. The number of phytoplanktons were 1700 individuals from 32 species and 3 classes, namely Bacillariophyceae, Chlorophyceae, and Cyanophyceae. The highest density is Bacillariophyceae 2214 ind/m3 (84\%) followed by Chlorophyceae 349 ind $/ \mathrm{m} 3$ (13\%) and Cyanophyceae $72 \mathrm{ind} / \mathrm{m} 3$ (3\%). The diversity index of Saluesem River phytoplankton is 2.92 categorized into middle diversity. Evenness Index is 0.64 showed equal distribution. There is no dominant species showed by dominance index is 0.18 . Based on diversity index $\mathrm{H}^{\prime}$ is 2.92 , water quality of Salusem River upstream are categorized into light pollution. Different sources of pollution were household, agriculture, animal husbandary activities.
\end{abstract}


Keywords: River Saluesem, structure phytoplankton, composition phytoplankton, water quality, North Sulawesi,

\section{PENDAHULUAN}

Sungai Saluesem termasuk perairan terbuka yang mengalir (lotik) yang berasal dari Gunung Mahawu yang terletak di Kota Tomohon, Minahasa dan bermuara ke Teluk Manado yang terletak di Kota Manado, Sulawesi Utara. Hulu sungai sebagai bagian pertama yang akan ditemui di sungai merupakan sumber awal aliran air. Hulu merupakan daerah konservasi tanah dan air. Saat bagian hulu sungai rusak maka seluruh bagian sungai akan rusak termasuk bagian tengah dan hilir. Aktivitas manusia yang terus meningkat di bagian hulu dapat menurunkan kualitas perairan. Penurunan kualitas dapat mempengaruhi struktur dan komposisi fitoplankton. Fitoplankton memiliki peranan penting bagi kehidupan di perairan karena merupakan produsen primer dalam rantai makanan.

Fitoplankton di sungai dapat dijadikan parameter biologis untuk mengevaluasi kualitas sungai karena fitoplankton memiliki batas toleransi tertentu dan respon yang berbeda terhadap perubahan parameter fisika dan kimia melalui perubahan keanekaragaman fitoplankton (Astriyana dan Yuliana, 2012).

Penelitian tentang struktur dan komposisi fitoplankton di Sungai Saluesem pada saat ini belum dilakukan, sedangkan aktivitas manusia dibagian hulu semakin meningkat. Oleh karena itu, perlu dilakukan penelitian tentang struktur dan komposisi fitoplankton di Sungai Saleusem bagian hulu.

\section{METODE PENELITIAN}

Penelitian dilaksanakan dari Oktober 2014 sampai Desember 2014. Lokasi pengambilan sampel pada penelitian ini dilakukan di hulu Sungai Saluesem Kabupaten Minahasa. Pengambilan sampel dilakukan pada dua stasiun yang dipilih secara purposif dengan mempertimbangkan aksesibilitas yang mudah dijangkau. Setiap stasiun ditentukan 3 titik pengambilan sampel dengan pengulangan sebanyak 3 kali pada setiap titik. Identifikasi sampel dilakukan di Laboratorium Ekologi Jurusan Biologi
Fakultas Matematika dan Ilmu Pengetahuan Alam, Universitas Sam Ratulangi Manado.

Alat yang digunakan antara lain plankton net ukuran 30 mesh, mikroskop digital berkamera dan Sedgewick-Rafter. Bahanyang digunakan yaitu larutan lugol dan terusi. Identifikasi dilakukan dengan menggunakan buku-buku identifikasi Edmonson (1966), Prescott (1978) dan Sachlan (1982). Bahanyang digunakan yaitu larutan lugol dan terusi.

Penelitian ini menggunakan metode purposive random samplingdalam menentukan titik-titik pengamatan. Total sampel fitoplankton bagian hulusebanyak 6 (enam) sampel.Pengambilan sampel dilakukan pada hari yang sama. Alat plankton net ditenggelamkan ke dalam air yang melawan arus selama 5 (lima) menit. Air yang telah tersaring dan masuk ke dalam kolektor plankton net tersebutdimasukkan ke dalam botol sampel yang sudah berisi larutan lugol dan terusi. Struktur dan komposisi yang dianalisis yaitu kekayaan jenis, distribusi, kepadatan, keanekaragaman, kemerataan dan dominansi.

\section{Kepadatan Fitoplankton}

Kepadatan fitoplankton dinyatakan dalam satuan individu/meter kubik (ind $/ \mathrm{m}^{3}$ ) dengan menggunakan rumus dari Wardhana (2003) : dengan :

$\mathrm{D}=(1 / \mathrm{p}) \mathrm{q}(1 / \mathrm{v})$

D: Kepadatan fitoplankton per satuan volume (Ind $\left./ \mathrm{m}^{3}\right)$

$\mathrm{q}:$ Jumlah individu

p: Volume sampel dalam Sedgwick Rafter (mL)

1 : Volume sampel yang tersaring $(\mathrm{mL})$

$\mathrm{v}$ : Volume air yang masuk dalam plankton net $\left(\mathrm{m}^{3}\right)$

\section{Keanekaragamaan Fitoplankton}

Keanekaragaman fitoplankton dihitung dengan menggunakan indeks keanekaragaman Shannon-Wiener (Magurran, 2004) yaitu:

dengan :

$$
\mathrm{H}^{\prime}=-\Sigma\left(\mathrm{p}_{\mathrm{i}} \ln \mathrm{p}_{\mathrm{i}}\right)
$$

H' : Indeks Keanekaragaman Spesies 
$\mathrm{p}_{\mathrm{i}}$ : Indeks Nilai Penting(INP) dari Spesies ke- i per Indeks Nilai Penting Total $\left(\mathrm{n}_{\mathrm{i}} / \mathrm{N}\right)$

$\mathrm{n}_{\mathrm{i}}$ : Indeks Nilai Penting (INP) dari Spesies ke- $\mathrm{i}$

$\mathrm{N}$ : Indeks Nilai Penting (INP) Total

Indeks keanekaragaman

dikelompokkan menjadi tiga kelompok yaitu tinggi $\left(\mathrm{H}^{\prime}>3\right)$, sedang $\left(1 \leq \mathrm{H}^{\prime} \leq 3\right)$ dan rendah $\left(\mathrm{H}^{\prime}<1\right)$ (Fachrul, 2007).

\section{Kemerataan Fitoplankton}

Indeks kemerataan fitoplankton ditentukan dengan rumus sebagai berikut: (Odum, 1996).

$$
\mathrm{E}=\mathrm{H}^{\prime} / \ln \mathrm{S}
$$

dengan :

$$
\begin{array}{ll}
\text { E } & \text { : Indeks Keseragaman } \\
\text { H, } & \text { : Indeks Keanekaragaman } \\
\text { S } & \text { : Kekayaan Spesies }
\end{array}
$$

Indeks kemerataan berkisar antara 0 sampai 1. Indeks mendekati 0 memiliki kemerataan spesies rendah atau penyebaran jumlah individu masing-masing spesies sangat jauh berbeda dan indeks kemerataan mendekati 1 memiliki kemerataan yang tinggi atau memiliki jumlah individu masingmasing spesies sama/tidak jauh berbeda (Odum, 1996).

\section{Dominansi Fitoplankton}

Indeks dominansi dihitung menggunakan rumus Simpson (Odum, 1996) berikut ini: dengan :

$$
\text { Dominasi }=\Sigma(\mathrm{ni} / \mathrm{N})^{2}
$$

Dominasi: Indeks dominansi Simpson

ni : Jumlah individu tiap spesies

$\mathrm{N} \quad$ : Jumlah individu semua jenis dalam komunitas

Indeks dominansi Simpson berkisar antara 0 sampai 1 . Nilai indeks dominansi yang makin kecil menunjukkan tidak ada spesies yang mendominansi. Nilai indeks dominansi yang makin besar sebaliknya menunjukkan ada spesies tertentu(Odum, 1996).

\section{HASIL DAN PEMBAHASAN}

\section{Kekayaan dan Kelimpahan Spesies Fitoplankton}

Fitoplankton yang didapatkan di hulu Sungai Saluesem sebanyak 1700 individu dari 32 spesiesdan 3 kelas. Kelas Fitoplankton yaitu Bacillariophyceae, Chlorophyceae, Cyanophyceae. Fitoplankton di bagian Hulu Stasiun I dan Stasiun II

\begin{tabular}{|c|c|c|c|}
\hline No. & Taksa & Stasiun I & Stasiun II \\
\hline 1. & Achnanthes sp. & + & + \\
\hline 2. & Actinastrum sp. & + & + \\
\hline 3. & Anabaena sp. & + & + \\
\hline 4. & $\begin{array}{l}\text { Ankistrodesmus } \\
\text { sp. }\end{array}$ & + & + \\
\hline 5. & Chroococcus sp. & + & - \\
\hline 6. & Closterium sp. & + & + \\
\hline 7. & Cocconeis sp. & + & + \\
\hline 8. & Coelastrum sp. & + & + \\
\hline 9. & Coscinodiscus sp. & + & + \\
\hline 10. & Cosmarium sp. & + & + \\
\hline 11. & Cymbella sp. & + & + \\
\hline 12. & Fragilaria sp. & + & - \\
\hline 13. & Gomphonema sp. & + & + \\
\hline 14. & Gonatozygon sp. & + & - \\
\hline 15. & $\begin{array}{l}\text { Kentrosphaera } \\
\text { sp. }\end{array}$ & + & - \\
\hline 16. & Mougeotia sp. & + & - \\
\hline 17. & Navicula sp. 1 & + & + \\
\hline 18. & Navicula sp. 2 & + & + \\
\hline 19. & Navicula sp. 3 & + & + \\
\hline 20. & Nitzschia sp. 1 & + & + \\
\hline 21. & Nitzschia sp. 2 & + & + \\
\hline 22. & Oscillatoria sp. & + & + \\
\hline 23. & Pleurosigma sp. & - & + \\
\hline 24. & Skeletonema sp. & + & + \\
\hline 25. & Spirogyra sp. & + & + \\
\hline 26. & Spirulina sp. & - & + \\
\hline 27. & Staurastrum sp. & + & - \\
\hline 28. & Surirella sp. & + & + \\
\hline 29. & Synedra sp. & + & + \\
\hline 30. & Terpsinoe sp. & + & - \\
\hline 31. & Ulothrix sp. & + & + \\
\hline \multirow[t]{2}{*}{32.} & Zygnemopsis sp. & + & - \\
\hline & $\mathbf{S}$ & 30 & 24 \\
\hline
\end{tabular}
ditemukan 917 individu, 30 spesies dan 783 individu, 24 spesies.

Tabel 1. Distribusi fitoplankton di Hulu Sungai Saluesem

Keterangan: (+) ditemukan; (-) tidak ditemukan $(\mathrm{S})$ kekayaan spesies 


\section{Distribusi Fitoplankton}

Fitoplankton yang ditemukan di hulu Sungai Saluesem sebanyak 32 spesies. Kehadiran spesies di tiap stasiun tidak sama. Fitoplankton yang ditemukan di Stasiun I berjumlah 30 spesies $(93,75 \%)$ dan di Stasiun II berjumlah 24 spesies (75\%).

Spesies yang tidak ditemukan di Stasiun I tetapi ditemukan di Stasiun II ada dua spesis yaitu Pleurosigma sp. dan Spirulina sp. Fitoplankton yang ditemukan di Stasiun I tetapi tidak ditemukan di Stasiun II berjumlah 8 spesies, yaitu Chroococcus sp.,Fragilaria sp.,Gonatozygon sp., Kentrosphaera sp., Mougeotia sp., Staurastrum sp., Terpsinoe sp. dan Zygnemopsis sp. Fitoplankton yang ditemukan di kedua stasiun berjumlah 22 spesies.

\section{Kepadatan Fitoplankton}

Kepadatan fitoplankton dari Kelas Bacillariophyceae menempati urutan pertama di hulu Sungai Saluesem dengan jumlah 2214 individu $/ \mathrm{m}^{3}$ (84\%). Kelas Chlorophyceae merupakan kelas kedua terbanyak, yaitu 349 individu $/ \mathrm{m}^{3}(13 \%)$. Urutan ketiga ditempati oleh Kelas Chlorophyceae dengan kepadatan 72 individu $/ \mathrm{m}^{3}(3 \%)$. Kepadatan fitoplankton di hulu Sungai Saluesem tampak pada Gambar 1.

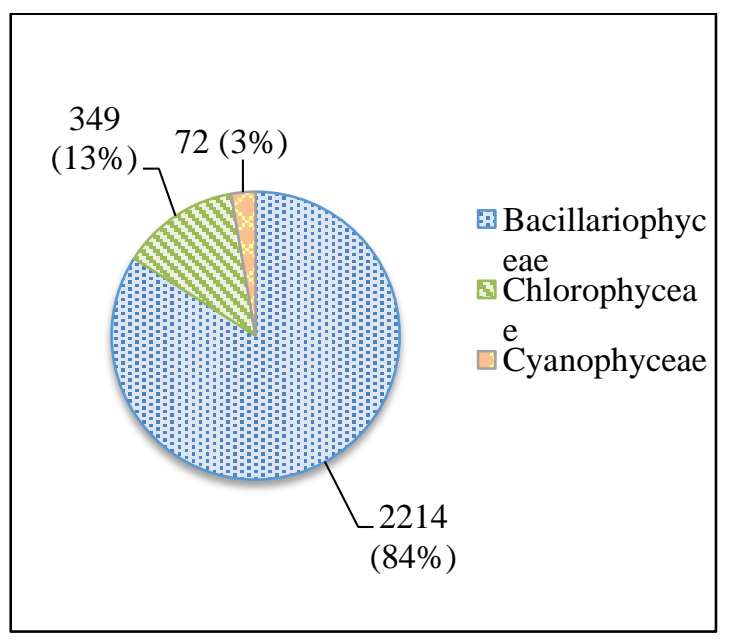

Gambar 1. Kepadatan fitoplankton di Hulu Sungai Salueseum

Kepadatan fitoplankton Kelas Bacillariophyceae lebih tinggi dibandingkan dengan kelas lainnya. Hal ini dikarenakan Kelas Bacillariophyceae memiliki kemampuan yang baik untuk beradaptasi dengan lingkungannya dibandingkan dengan fitoplankton lainnya (Yuliana et al., 2012; Samsidar et al., 2013). Nontji (2008) juga melaporkan bahwa diatom yang termasuk dalam Kelas Bacillariophyceae merupakan kelompok fitoplankton yang paling banyak dijumpai di perairan. Hal ini disebabkan karena kelompok ini memiliki kemampuan yang baik untuk beradaptasi dengan kondisi lingkungan yang ada di sekitarnya serta memiliki penyebaran yang luas.

\section{Keanekaragaman Fitoplankton}

Indeks keanekaragaman pada kedua stasiun pengambilan yaitu Stasiun I(H': 2,91) dan Stasiun II (H': 2,79). Indeks keanekaragaman di bagian hulu yaitu H': 2,92 (Gambar 2).

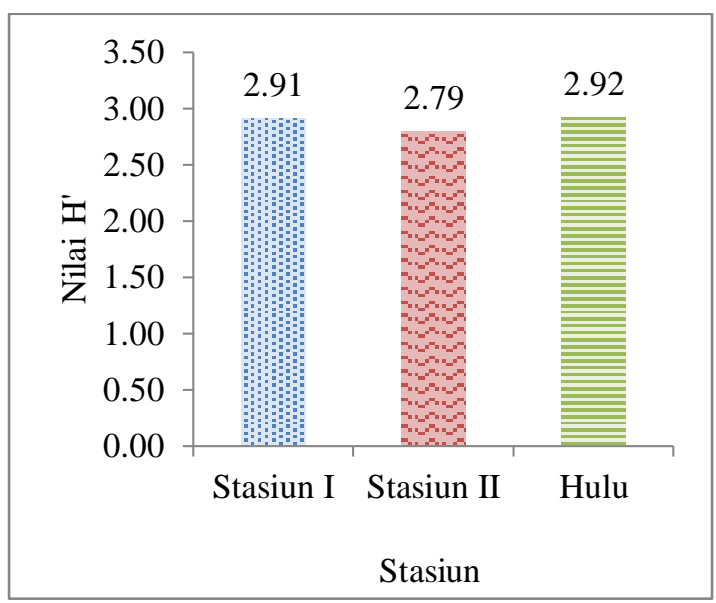

Gambar 2. Indeks keanekaragaman fitoplankton

Nilai keanekaragaman spesies pada kedua stasiun pengambilan pada kisaran yaitu $1 \leq H^{\prime} \leq 3$. Berdasarkan kiteria Fachrul (2007), keanekaragaman fitoplankton di bagian hulu Sungai Saluesem termasuk sedang. Kualitas air sungai yang tidak sesuai untuk menunjang pertumbuhan dan perkembangan menjadi faktor penyebab rendahnya keanekaragaman karena dapat menurunkan jumlah jenis dan jumlah individu pada perairan tersebut (Samsidar, 2013). Fitoplankton yang dapat bertahan hidup pada kondisi perairan tersebut merupakan spesies yang mampu beradaptasi dan memiliki toleransi yang tinggi (Asriyana dan Yuliana, 2012).

\section{Kemerataan Fitoplankton}

Kemerataan spesies menunjukkan ada tidaknya spesies yang merata pada setiap stasiun. Indeks kemerataan (E) di Sungai 
Saluesem di Stasiun I ialah 0,63 dan di Stasiun Ilialah 0,67. Indeks kemerataan di bagian hulu Sungai Saluesem adalah 0,64 (Gambar 3).Nilai indeks kemerataan di perairan Sungai Saluesem mendekati angka 1 menunjukkan bahwa adanya spesies fitoplankton yang merata atau penyebaran yang dimiliki masing-masing spesies tidak jauh berbeda.

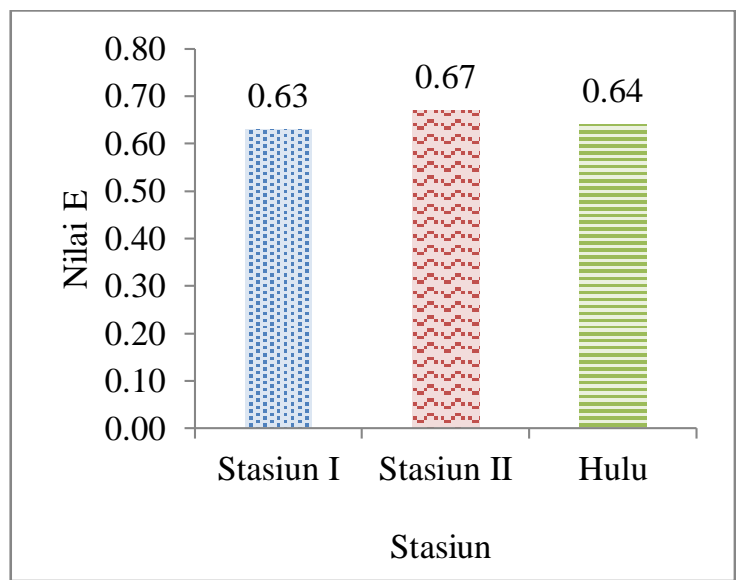

Gambar 3. Indeks kemerataan fitoplankton

\section{Dominansi Fitoplankton}

Nilai indeks dominansi (D) fitoplankton yang ditemukan di Stasiun Iadalah 0,20 dan Stasiun IIadalah 0,18. Nilai indeks dominansi fitoplankton di bagian hulu Sungai Saluesem yaitu 0,18 (Gambar 4).

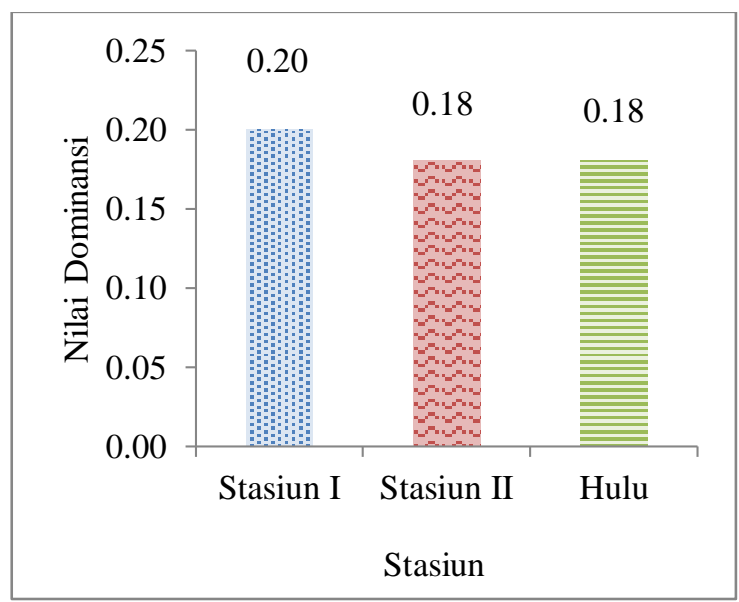

Gambar 4. Indeks dominansi di Bagian Hulu Sungai Saluesem

Hasil penelitian menunjukkan nilai dominansi masing-masing di titik pengambilan mendekati angka 0 yang artinya tidak adanya spesies yang mendominasi perairan Sungai Saluesem walaupun terdapat beberapa spesies yang selalu muncul pada setiap stasiun dengan jumlah individu yang besar. Rendahnya indeks dominansi disebabkan karena keanekaragaman di Sungai Saluesem termasuk dalam kategori sedang sesuai dengan kriteria Fachrul (2007). Nilai indeks dominansi berbanding terbalik dengan keanekaragaman. Jika indeks dominansi tinggi maka indeks keanekaragamannya rendah dan sebaliknya (Odum, 1996).

\section{KESIMPULAN}

Fitoplankton yang didapatkan di bagian hulu Sungai Saluesem berjumlah 1700 individu, 32 spesies dan 3 kelas. Kelas Bacillariophyceae merupakan kelas yang paling banyak ditemukan di bagian hulu diikuti Kelas Chlorophyceae dan Cyanophyceae. Kepadatan tertinggi berasal dari Kelas Bacillariophyceae 2214 individu $/ \mathrm{m}^{3} \quad(84 \%)$ diikuti Kelas Chlorophyceae 349 individu/m $\mathrm{m}^{3}(13 \%)$ lalu Cyanophyceae 72 individu $/ \mathrm{m}^{3}$ (3\%). Indeks keanekaragaman di hulu Sungai yaitu 2,92 yang menunjukan keanekaragaman sedang. Indeks kemerataan mendekati angka 1 yaitu 0,64 menunjukan spesies fitoplankton merata. Indeks dominansi yaitu 0,18 yang menunjukan tidak ada spesies yang mendominasi.

\section{DAFTAR PUSTAKA}

Asriyana dan Yuliana. 2012. Produktivitas Perairan. Bumi Aksara. Jakarta.

Edmondson, W.T. 1966. Freshwater Biology. Second Edition. University of Washington. Seattle.

Fachrul, M.F. 2007. Metode Sampling Bioekologi. Bumi Aksara. Jakarta.

Magurran, A. E. 2004. Measuring Biological Diversity. Blackwell Publishing. Victoria.

Nontji, A. 2008. Plankton Laut. Lembaga Ilmu Pengetahuan Indonesia (LIPI) Press. Jakarta.

Odum, E.P. 1996. Dasar-Dasar Ekologi. Edisi Ketiga. Gadja Mada University Press. Yogyakarta.

Prescott, G.W. 1978. Freshwater Alga. Third Edition. Wm C Brown Company Publishers. Dubuque. 
Sachlan, M. 1982. Planktonologi. Fakultas Peternakan dan Perikanan. Universitas Dipenogoro. Semarang.

Samsidar, Kasim. M., Salwiyah. 2013. Struktur Komunitas dan Distribusi Fitoplankton di Rawa Aopa Kecamatan Angata Kabupaten Konawe Selatan. Jurnal Mina Laut Indonesia. 2(6): 109-119.

Wardhana, W. 2003. Teknik Sampling, Pengawetan, dan Analisis Plankton. Disampaikan pada : Pelatihan Teknik Sampling dan Identifikasi Plankton. Balai Pengembangan dan Pengujian Mutu Perikanan. 